\title{
Tick-borne encephalitis joins the diseases under surveillance in the European Union
}

A J Amato-Gauci (andrew.amato@ecdc.europa.eu)'1, H Zeller ${ }^{1}$

1. European Centre for Disease Prevention and Control, Stockholm, Sweden

Citation style for this article:

Amato-Gauci AJ, Zeller H. Tick-borne encephalitis joins the diseases under surveillance in the European Union. Euro Surveill. 2012;17(42):pii=20299. Available online: http://www.eurosurveillance.org/ViewArticle.aspx?Articleld=20299

Climate and environmental changes are suspected as major determinants that alter the distribution and transmission patterns of certain communicable diseases, especially those transmitted by arthropods, such as ticks (e.g. tick-borne encephalitis (TBE) and Lyme disease), mosquitoes, (e.g. Chikungunya and Dengue fever), or sandflies (e.g. visceral leishmaniasis). Apart from the effect on the natural conditions and favouring a wider distribution of vectors which may carry diseases, they can also influence occupational and recreational human behaviour and lead to an increased exposure to the risk of infectious diseases e.g. through increased time spent outdoors and harvesting food in woodlands with high concentrations of ticks [1-3].

In the European Union (EU), climate and environmental changes are believed to be a cause for the recent resurgence of 'old suspects' such as malaria, as well as the geographic expansion of diseases like West Nile fever or TBE [4].

On 5 September 2012, TBE was included in the list of notifiable diseases in the EU. The main European Commission Decisions on communicable diseases were amended to include TBE in the list of diseases for EU notification, along with it's own new case definition [5-7].

In 2011, TBE was already mandatorily notifiable in 15 European Union (EU) and European Economic Area (EEA) countries [8]. However, a reliable estimate of the incidence of TBE is not available due to differences in diagnosis, case definition and reporting in different endemic countries. Thus, the overall epidemiology and burden of tick-borne encephalitis in Europe remains unclear [8].

The aim of the new, common case definition is to provide high validity and good comparability of TBE data from the EU Member States to be able to better study this disease. It is hoped that reliable surveillance data will help in better mapping the disease risk. Such information available at the EU level should also facilitate development of more efficient prevention and control programmes at both national and international levels.

Tick-borne diseases are the most common vectorborne diseases in Europe with their infection rate and geographic distribution in Europe increasing since the 1980 's. TBE is a viral tick-borne communicable disease that occurs in endemic areas across large regions of Europe and also in Asia. Most human cases occur following a bite by an infected tick. Consumption of raw milk and derived products is another mode of transmission of the disease [9]. The vectors of TBE virus in Europe are Ixodidae hard ticks, mainly Ixodes ricinus in central, northern and eastern regions and Ixodes persulcatus in parts of the Baltic States, Finland, and in Russia. The cycle of transmission of the virus includes reservoir hosts which are mainly small rodents.

TBE infection is described as a febrile influenza-like illness usually lasting 2 to 4 days followed by a symptom-free interval lasting a few days. For an estimated $\mathbf{2 0 - 3 0 \% ~ o f ~ t h e ~ p a t i e n t s ~ i t ~ e v o l v e s ~ i n ~ a ~ n e u r o i n v a s i v e ~}$ illness (e.g. meningitis, meningoencephalitis, meningoencephalomyelitis or meningo-radiculitis) which appears suddenly [9]. Every year, the TBE virus causes thousands of cases of neuroinvasive illness in humans across Europe and Asia and is becoming a growing public health concern despite that the disease is preventable by vaccination [10]. The true burden of the disease at EU level still has to be established even though it is known that TBE demands high costs for healthcare systems with intensive care in hospitals, and it's possible long-lasting sequelae [8].

\section{Enhanced surveillance is needed to prevent and control TBE}

The distribution of TBE cases in Europe indicates areas with different levels of endemicity. A harmonised approach for case reporting will allow for endemic foci mapping within the EU to support recommendations regarding identified risk groups of population, vaccination programmes, and recommendations for travellers [11]. In a majority of cases the location of infection by tick bites would not be precisely recorded from the patient but cross-linking information should increase 
the mapping accuracy and the detection of changes in pattern distribution. In addition, various surveillance strategies, including screening of vector ticks and testing of animal hosts, should be better harmonised and be done more systematically in Europe to better understand the changing patterns of TBE.

Large amounts of environmental and epidemiological data are already collected in databases in the EU, which are mostly publicly available. However, these data are not brought together for analysis. ECDC is developing a European Environment and Epidemiology (E3) Network with an aim to better integrate environmental and disease data to increase our understanding of their complex relationships and to drive public health action. In the context of its mandate, ECDC is looking at possibilities to improve monitoring systems, that have the capability to connect epidemic intelligence and infectious disease surveillance data that are collated and hosted by ECDC, with meteorological variables, water quality records, air quality measures, remote sensing information, agricultural practices, etc.

At European level, ECDC is also pursuing how best to expand networks working in vector surveillance to monitor the distribution of vectors, for example tick species such as Ixodes ricinus vector of TBE and Lyme borreliosis or Hyalomma marginatum, a main vector of Crimean-Congo hemorrhagic fever. Enhancing global and regional surveillance and control of disease vectors has started in Europe in the VBORNET project since 2010 [4].

The new case definition and notifications of TBE together with a range of other surveillance activities are an important step to continue to improve the level of evidence on TBE in Europe to better help guide policies and measures to lower the burden of this vaccinepreventable disease.
References

1. European Centre for Disease Prevention and Control (ECDC) ECDC Technical Document. Climate change and communicable diseases in the EU Member States. Handbook for national vulnerability, impact and adaptation assessments. Stockholm: ECDC; 2010. Available from: http://www.ecdc.europa. eu/en/publications/Publications/1003_TED_handbook climatechange.pdf

2. Semenza IC, Menne B. Climate Change and Infectious Diseases in Europe. Lancet Infect Dis. 2009;9(6):365-75.

3. Stefanoff P, Rosinska M, Samuels S, White DJ, Morse DL, Randolph SE. A National Case-Control Study Identifies Human Socio-Economic Status and Activities as Risk Factors for TickBorne Encephalitis in Poland. PLoS One. 2012;7(9):e45511

4. European Centre for Disease Prevention and Control (ECDC). Network of medical entomologists and public health experts (VBORNET). Stockholm: ECDC. [Accessed 18 Oct 2012]. Available from: http://www.ecdc.europa.eu/en/activities/ diseaseprogrammes/emerging_and_vector_borne_diseases/ Pages/VBORNET.aspx

5. European Commission. Commission Decision 2002/253/EC of 19 March 2002 laying down case definitions for reporting communicable diseases to the Community network under Decision No 2119/98/EC of the European Parliament and of the Council. EC; 2002. Official Journal of the European Union. Available from: http://eur-lex.europa.eu/LexUriServ/ LexUriServ.do?uri=0J:L:2002:086:0044:0062:EN:PDF

6. European Commission. Decision No 2119/98/EC of the European Parliament and of the Council of 24 September 1998 setting up a network for the epidemiological surveillance and control of communicable diseases in the Community. EC; 1998. Official Journal of the European Union. Available from: http:// eur-lex.europa.eu/LexUriServ/LexUriServ.do?uri=CELEX:31998 D2119:EN:HTML

7. European Commission. Commission Decision of 22 December 1999 on the communicable diseases to be progressively covered by the Community network under Decision No 2119/98/EC of the European Parliament and of the Council (notified under document number C(1999) 4015) (2000/96/ EC). EC; 2000 . Official Journal of the European Union. Available from: http://eur-lex.europa.eu/LexUriServ/LexUriServ.do?uri= CONSLEG:2000D0096:20120905:EN:PDF

8. European Centre for Disease Prevention (ECDC). Epidemiological situation of tick-borne encephalitis in the European Union and European Free Trade Association countries. Stockholm: ECDC. Sep 2012. Available from: http:// www.ecdc.europa.eu/en/publications/Publications/TBE-in-EUEFTA.pdf

9. European Centre for Disease Prevention (ECDC). Tick-borne encephalitis. Factsheet for health professionals. Stockholm: ECDC. 16 Jun 2010. Available from: http://ecdc.europa.eu/en/ healthtopics/tick_borne_diseases/tick_borne_encephalitis/ basic_facts/Pages/factsheet_health_professionals.aspx

10. Kollaritsch H, Krasilnikov V, Holzmann H, Karganova G, Barrett A, Suss J, et al. Background Document on Vaccines and Vaccination against Tickborne Encephalitis (TBE). World Health Organization; 2011. Available from: http://www.who.int/ immunization/sage/6_TBE_backgr_18_Mar_net_apr_2011.pdf

11. Donoso Mantke O, Escadafal C, Niedrig M, Pfeffer M, on behalf of the Working group for Tick-borne encephalitis virus. Tick-borne encephalitis in Europe, 2007 to 2009. Euro Surveill. 2011;16(39):pii=19976. Available from: http://www. eurosurveillance.org/ViewArticle.aspx?Articleld=19976 